Encouraging Critical Thinking in the Classroom: An Example from Aesthetics

Marilyn DeLong, Jane Hegland, Nancy Nelson

DeLong, Marilyn R., Hegland, Jane E., \& Nelson, Nancy J. (1997). Encouraging critical thinking in the classroom: An example from Aesthetics. Clothing and Textiles Research Journal, 15(2), 86-95.

Made available courtesy of SAGE Publications: http://ctr.sagepub.com/

***Note: Figures may be missing from this format of the document

\begin{abstract}
:
This paper illustrates how critical thinking techniques could be used in teaching aesthetics. Exploring unfamiliar territory and moving freely between reflective and active thought processes are components important to both aesthetics and critical thinking. In keeping with the objectives of critical thinking, a classroom exercise titled "Getting Outside of Your Own Skin" was designed to help students acknowledge and address assumptions and biases they may hold about older consumers and the aging process. Students were encouraged to move beyond personal experiences to broaden their thinking about individuals unlike themselves. By working through the project, students were given the opportunity to examine their perceptions and attitudes toward the aging process and to consider their effect on this growing market.

Key Words: aesthetics, critical thinking, age stereotypes, pedagogy
\end{abstract}

\title{
Article:
}

Many perceptions about our world become fixed due to the limited nature of our personal experiences. This makes it difficult to be understanding or empathetic to the needs of those individuals who are different from us. Students studying the design, production, or distribution of clothing need to develop the ability to transcend their own experiences and preferences to understand those individuals they will serve. They need the skills to perceive and interpret changing markets. Bass, Kutza and Torres-Gil (1990) project that the nature of the population within 21st century America will reflect a rapid increase in the number of elderly people of all ethnic and racial groups. Such projections point toward a multicultural American market that will be focused on meeting the needs of the older individual. Futurists, Alvin and Heidi Toffler (1995), have described their "Third Wave" sector as a demassified society where production and marketing would be highly customized. This concept differs significantly from mass production and mass merchandising that is prevalent today. To serve such a demassified society would require a paradigm shift. Our clientele would no longer need to be categorized by classifications of height, size, age, or gender, but could be treated more individually. Such paradigm shifts require critical thinking skills.

The classroom provides an ideal setting for helping students learn critical thinking skills to move outside of their personal experiences, and thereby broaden their thinking. We developed an exercise which combined concepts from critical thinking theory and aesthetic theory, where students would encounter their own perceptions and attitudes and thereby explore personal assumptions. In this exercise, students were asked to transcend their current age and life- 
experiences by imagining themselves at age 70, and thereby question perceptions of the aging process. The exercise, entitled "Getting Outside of Your Own Skin," seemed an ideal way for students to begin to understand the clothing market for consumers who are different from themselves. Through focused responses, we were able to analyze students' perceptions of themselves as younger consumers as compared to what they perceived they might be like as older consumers.

Brookfield (1987) believes that all classroom experiences should include critical thinking. He developed four criteria for critical thinking which were used in the development of the class project: (a) to identify and challenge assumptions, (b) to become contextually aware, (c) to imagine and explore alternatives and (d) to engage in reflective skepticism. These criteria were used throughout the analysis of student responses because they were readily integrated with the process of understanding aesthetics.

When compared, aesthetics and critical thinking have a number of characteristics in common. Important to each is to begin with the familiar and move toward the unfamiliar. Also, both require the ability to move freely between reflective and active thought processes. In this project, students were faced with imagining the selection of clothing for themselves at age 70 . Such a dilemma is part of the process of critical thinking, wherein the students begin to question their own perceptions of a paradigm that may be unfamiliar to them. Thus the synergistic relationship between critical thinking and aesthetics was used.

\section{Review of Literature}

In the process of developing this class project, three areas of literature were searched to create a framework from which to work: critical thinking, aesthetic response to clothing, and age stereotypes of the older consumer.

\section{Critical Thinking: Definition and Application}

Critical thinking is usually defined as a process which contains a number of levels of analysis. As Ennis (1993) states: "critical thinking is reasonable reflective thinking focused on deciding what to believe or do (p. 180)." Scholars in the area of critical thought (Brookfield, 1987; McPeck, 1990; Menefee, 1987; Paul, 1992) discuss the possibilities of going beyond association in the learning process, moving toward a more rational thought process that seeks validity through analysis. Critical thinking can help to form habits of logical reflection, wherein an individual questions what is read and heard in such a way as to form logical, as well as associative, connections.

Many scholars in the area of critical thought believe that students are taught passivity (Chaffee, 1992; Halpern, 1993; Knight, 1992; Laughlin, 1992; Ruggiero, 1988). They suggest that the typical model used in higher education-transfer of information from teacher to student- does not allow for development of higher-order thinking skills. A classroom situation that fosters sound argumentation between teacher and students will create more possibilities for autonomous thinking on the part of students (Chaffee, 1992; McPeck, 1990). Such skills will not only help students within an academic context, but within personal and professional contexts as well. Adaptability to frequent change in a rapidly changing job market is one positive result of developing critical thinking skills (Halpern, 1993). Knight (1992) proposes the best possible 
outcome for critical thinking in the classroom: "Optimally, the teaching of thinking should produce a critical and creative disposition that enables a person to transcend biases, evaluate situations and ideas objectively, and create habits of mind that extend beyond academics to life experience in general"' (p. 64).

Through critical thinking, individuals can challenge biased and associative social and cultural stereotypes. Decisions become based upon rational analyses. McPeck (1990) believes that critical thinking is not a content-free general ability, nor a set of specific skills. Through reasoning and argument, one is led to an understanding of how practices, actions, and structures are shaped by contexts. Brookfield (1987) writes that critical thinking requires the "suspension of belief and the jettisoning of assumptions previously accepted without question" (p. 10). Criti cal thinking allows for diversity of values, beliefs, behaviors, and experiences in the world. By becoming conscious of diversity, an individual gains a sense of the 'realness' of others.

At the same time that critical thinking fosters rational thought processes, it uses creative imagination. To understand diversity of experiences, reason needs to be combined with emotion, as the ability to be empathetic of others' beliefs and values allows for a deeper understanding of social and cultural differences. This critical and reflective analysis will often result in a new perspective, one in which imagination plays a vital role. Walters (1990) believes that the model of rationality should contain both analytic and imaginative processes. Logic and analysis are not enough; creativity, imagination, and brainstorming contribute to a more holistic approach to critical thought as well as a re- visioning of the future (Walters, 1990). Action results from the realization that there is power to change through intellect and imagination.

Brookfield (1990) proposes that the primary and ultimate purpose of teaching is to foster critical thinking skills. In-class simulations are discussed as a means of prompting three elements of critical thinking: contextual awareness, imaginative speculation, and assumption analysis. In addition, as Gallo (1989) points out, critical thinking and creative thinking are linked; emotions such as empathy can be beneficial to the reasoning process. She writes that empathy contains both cognitive and affective dimensions. Through role-playing and projection, or "putting oneself in the place of another and anticipating the behavior of the other, or the imaginative transposing of oneself into the thinking, feeling, and actions of another" (Gallo, 1989, p. 100), students learn to use their imaginative capabilities to better understand diverse perspectives.

Because it is important that students become open to and aware of new perspectives, critical thinking requires separation from previously held beliefs; however, being critical of one's own view can sometimes cause stress and discomfort (Gallo, 1989). To reconstruct students' thinking processes to allow for creation of a deeper understanding of others is a challenge central to critical-creative thought (Brookfield, 1987; Gallo, 1989).

\section{Aesthetic Response: Definition and Practice}

A task of aesthetics is to understand how we perceive and understand our responses to clothing. This includes understanding underlying assumptions about how we respond to images, our values, preferences, and cultural biases (DeLong, 1987). Aesthetic response includes knowledge and understanding of three aspects which interrelate and influence each other: the viewer, the form, and the context of viewing (Eaton, 1988; Munro, 1956). 
The viewer may be the wearer of a clothing ensemble looking in a mirror, or the viewer of another person other than oneself. He or she brings to the interaction both personal traits and experiences as well as those shared through cultural orientations and expectations. How we believe we should look and the image we would like to project are ideals which influence our viewing habits.

The form is defined as a distinctive arrangement of surfaces, lines, and shapes; in this instanceclothing on the body. To describe this form, we traditionally speak of the features of clothing, however, reference should be made to all materials arranged on the wearer's body including shoes and accessories as well as manipulations of the body such as hair and cosmetics. Fiore, Moreno and Kimle (in press) include formal, expressive, and referential aspects and this involves viewing directly perceived features and indirectly experienced content. In addition, the concept of the Gestalt-that the whole is more than the sum of its parts-must be kept in mind in the viewing process (Amheim, 1974).

Finally, viewing contexts refer to immediate physical space and cultural milieu. The immediate physical space includes lighting, neighboring objects, and accompanying objects. The cultural milieu involves trends in tastes, values, and place of fashion within culture. In an ideal exercise that explores the nature of aesthetic response, the interaction of the viewer, the form, and the context would be included.

\section{Age Stereotypes and the Older Consumer}

Consumer groups that are growing rapidly require interpretation within clothing markets, as changing demographics require an understanding of changing needs and preferences. One rapidly increasing market segment is the one defined by age-the over-55 market. The 1990 United States Census indicates that a significant part of the population consists of people over the age of 55 . With more than $21 \%$ of the total U.S. population in this age group at present, and considering the projected increase to almost $33 \%$ by the year 2025 (Bos, Vu, Massiah, \& Bulatao, 1994), special emphasis should be placed on understanding their needs.

Levin (1988) defines stereotypes as "exaggerations of reality that are applied to entire groups of people" (p. 146). This definition is highlighted by results of some research on old-age stereotyping whereby evaluations of older people as a group are more negative than evaluations of older individuals. Tibbitts (1979) found that older people continue to seek fulfillment in life by staying active through education, politics, volunteer work, and paid employment. Such findings challenge the stereotypical notion that elderly are an economic and social burden to the rest of society.

Fennell (1994), writing about the meaning of aging, discussed how individuals of varying ages deal with cultural stereotypes about the aging process. She recorded how people of various ages responded to the process of aging within a cultural context; in this case, a southern town. She found a negative view of aging is more apt to be in the eye of the younger person because rewards of aging, which may be apparent to older people, are not so clear to younger people. Being current with tastes and fashions within the larger society was more often mentioned as a positive characteristic associated with younger age groups and older members were often 
characterized as old-fashioned by younger generations. While interviewees suggested that age categories of "middle-aged" and "old" had negative connotations, when they thought of specific individuals, their evaluations belied the category. Any one person could be described as both young and old at one time or another.

Old-age stereotypes are often reinforced through media. Media representations reflect general notions of what an older person is like, and tend to use imagery that does not recognize individual differences between members of this age group (Powell \& Williamson, 1985). The elderly are in the most contact with all media forms, however, as an age group, they tend to be under-represented in the media relative to the total population, suggesting that this age group is unimportant in U.S. culture (Atkins, Jenkins, \& Perkins, 1990; Powell \& Williamson, 1985). Though retired persons may not be "gainfully employed," it is not true that they have less buying power.

Bassili and Reil (1981) suggest that because younger people are assumed to have less exposure to the elderly, they may lack differentiated impressions of them. By contrast, exposure to elderly peers enjoyed by older adults may sensitize them to the distinctiveness of individuals. Thus, one way to reduce the influence of negative stereotyping has been to provide ample exposure to individuals who tend to be stereotyped.

The consequences of exposure to stereotypical images of older people are illustrated in results of four studies of the impact of old-age stereotypes on younger people's perceptions of the aging process. Each study used responses of college students in their early twenties as data to illustrate how the younger generation may view the older generation in America. In the first study, Levin (1988) manipulated a photograph of the same person to create three different ages and asked college students to respond to the images on semantic scales. The students who participated in the study attributed more negative qualities to the 73-year-old photograph than to the 25- and 52year-old examples. In the second study, 61 stereotype differential scales were used to measure attitudes of respondents to 12 "target categories." The categories contained two pieces of information; one was age designation and the other was either a gender, occupational, or ethnic label. Results indicated that 70- year-olds as an age group, regardless of gender, occupation, or ethnicity, were perceived by younger students to be traditional, conservative, moral, and presentoriented rather than future-oriented (Bassili \& Reil, 1981). In the third study, female college students in their early twenties responded to photographs of women of different ages in identical clothing. In their rating of fashionability, the ensemble was perceived to be more fashionable when worn by the younger-aged model (Clayton, Lennon, \& Larkin, 1987). In the fourth study, Workman and Johnson (1989) examined the role of clothing in perpetuating ageism. Students responded to eight photographs of an elderly male and female each photographed in a jacket and shirt. Variables manipulated were: coordinated or uncoordinated, and stained or unstained. Responses of the students were most favorable toward the elderly male in an unstained, coordinated jacket and shirt. The results of this study imply that appearance cues of an elderly individual will influence a younger person's perceptions of his or her character. Such studies provide insight into some possible reasons why older consumers are often times neglected.

The apparel industry tends to cater to a younger market, and this may influence an older consumer's perceptions. In a recent study focused on women of age 55 and over as catalog 
shoppers (Shim \& Bickle, 1993), results indicated a strong overall dissatisfaction not only with fit of garments purchased, but also with variety of product selection, including variety in style selection, colors, and fabric prints. Specifically, a woman's body changes physiologically over time, often resulting in the shortening of body, including trunk and sitting height, overall widening of the trunk, and changes in upper back and upper front width. If clothing marketers do not recognize the changes of aging women's bodies, then the older female consumer will continually compare herself to the fit ideal of youth, which in turn can cause dissatisfaction of appearance for many older women (Jackson \& O’Neal, 1994).

Thus three areas of literature shape the larger picture of the process of the learning exercise. Critical thinking allows for the possibility of moving beyond stereotypical imagery by dealing with the aging process on an individual level. Information on age stereotypes, such as images of older people presented by the media and studies using college age respondents, help point to the need for a more in-depth understanding of older consumers. Combined with the idea of aesthetic response within a cultural context, students were asked to face their own possible biases toward this age group and to treat themselves as the older fashion consumer.

\section{Methodology: The Learning Experience}

In keeping with the objectives of critical thinking, a classroom exercise titled "Getting Outside of Your Own Skin" was designed as part of a course on aesthetics to help students acknowledge and address assumptions and biases they may hold about older consumers and the aging process. The project was completed by juniors and seniors in a large midwestem university in a metropolitan area in 1991 and 1992. The 74 students (69 females and 5 males) who completed the exercise were working toward a career in the apparel industry either as designers or as retailers. Sixty-seven of the students were Caucasian and 7 were non-Caucasian. Ages of students ranged from 19 to 44: with 65 falling between the ages of 19 and 25. Sixty students indicated that they worked either part- or full-time in areas related to their major.

The two-part exercise in developing an aesthetic awareness began with something familiar to the students, and then proceeded to the unfamiliar. In "Part One" of the exercise, students were asked to consider themselves currently, by responding to questions designed to encourage them to focus on their present age. Then students were asked to select a specific event and to plan an appropriate ensemble for the designated event at their present age, taking into account their image goals, physical attributes, and personality characteristics.

In "Part Two" of the exercise, students were asked to respond to the same questions as in "Part One," only this time they were to imagine themselves at age 70. Then students were asked to plan an ensemble for the same event selected in "Part One," but this time the ensemble had to be appropriate for them at age 70 and the plan had to include their projected image goals, physical attributes, and personality characteristics.

\section{Description of the Questions}

In the first section of "Part One" and "Part Two" students were asked to respond to a series of questions about image goals and what they consider they are or would be like in terms of physical attributes and personality characteristics now and at age 70. Questions in this section were both closed- and open-ended. An example of a closed-ended question that explored 
personality characteristics involved the same checklist of 60 adjectives for each of the age categories.

Directions for the adjective selection were: "Describe how you want to look by marking the following adjectives." This list of adjectives had been developed and tested by students in earlier sections of the course, so applicability of terms was previously established (see figures \#1-4 for examples of some of these adjectives). Students could select as few or as many adjectives as they thought applied. For personality characteristics, responses ranged from 8 to 59 out of 60, with an average of 25 adjectives marked for both now and age 70 . For physical attributes, responses ranged from 4 to 39 out of 51, with an average of 15 adjectives designated for both now and age 70 .

Other closed-ended questions were used on a nine- point Likert scale. For example, the students were asked to respond to the statement: "I think being in fashion is..." Students responded on the scale between "very important" and "not important at all", both at their present age and again by imagining themselves at age 70. Examples of open- ended questions that required written responses were: "What colors do you prefer?" and "Describe briefly your occupation and/or lifestyle." Students were asked to respond to the same questions at both their present age and age 70. Written responses of the 67 students were analyzed for similarities and differences in their collective use of descriptors.

The second section of "Part One" and "Part Two" began with a set of questions designed to help the students select a specific event and plan an ensemble for it. Students planned an ensemble they would wear to the designated event at their current age. Then they were asked to think of themselves at age 70 and plan an ensemble for the same event, except as though they were 70 years of age. Events selected by the 74 students varied widely but the constancy of event across age was maintained. Students came up with the following ideas: a special events' party (17); their attendance at an orchestral or theatrical performance (14); a wedding (13); a casual outdoor summer event (9); a church- related event (5); a professional situation (7); an opening of an art exhibition (3); a casual outdoor winter event (2); and miscellaneous (4). The students were asked to justify their selection based on how they responded to the questions in the first section where they were asked to envision image goals, physical attributes, and personality characteristics for themselves at age 70 .

Fostering critical thinking skills requires an understanding of the assumptions and biases which underlie particular perspectives. As a way of working toward an understanding of biases and assumptions about older adults held by younger adults, the responses of 67 students who completed the exercise were analyzed. Students' responses were evaluated based on how they completed the exercise. The primary aspects we considered when assessing the success or failure of the project in developing critical thinking about aesthetic issues were: the depth and breadth of their justifications for choices, the relationship between responses to questions and decisions, and the continuity between current age and age 70. By analyzing the data, we realized that students perceived the aging process differently from one another. Through class discussion following the completion of the project, students began to realize the implications of their decisions and justifications. 


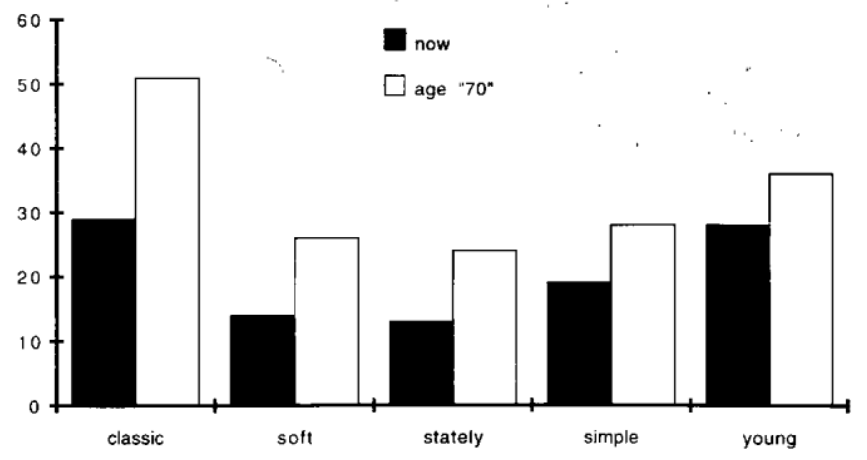

Figure 2. Comparison of responses to selected physical impressions: Summary of greatest increases from now to age 70.

\section{Collective Responses to Students' Perceptions of the Aging Process}

Analysis of responses to questions in "Part One" gave us a general sense of students' perceptions about the aging process through a comparison of responses to the same questions in "Part Two". For example, the most repeated responses to the statement: "Describe briefly your occupation and lifestyle" were "attend school full-time" at present age and "retirement" and "travel" in the age 70 responses. This may reflect the current status of elderly and therefore be stereotypical, even though in a positive way. This type of response is based on an assumption that the socioeconomic context will remain the same for students when they reach retirement age as it is currently for comfortably retired persons. This kind of response helped us to analyze responses to other questions, as it indicated that students perceive a major change in their lifestyle; in effect, students believed they would be living more leisurely at age 70 .

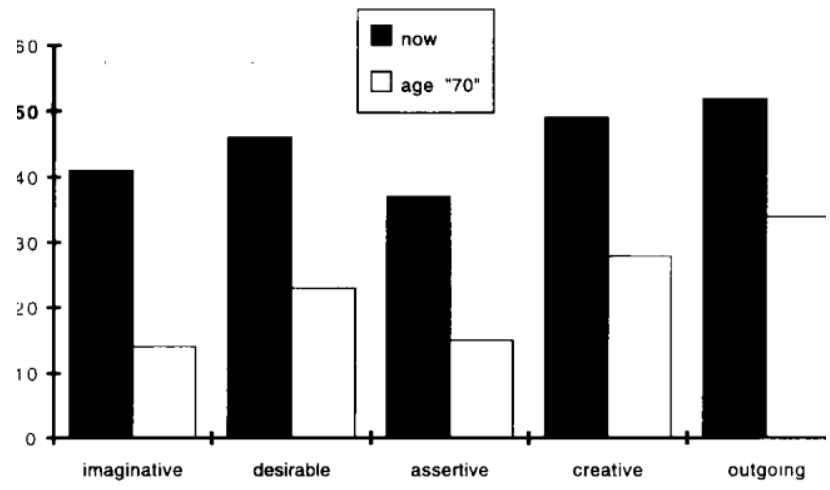

Figure 3. Comparison of responses to selected personali characteristics: Summary of greatest decreases fro now to age 70. 


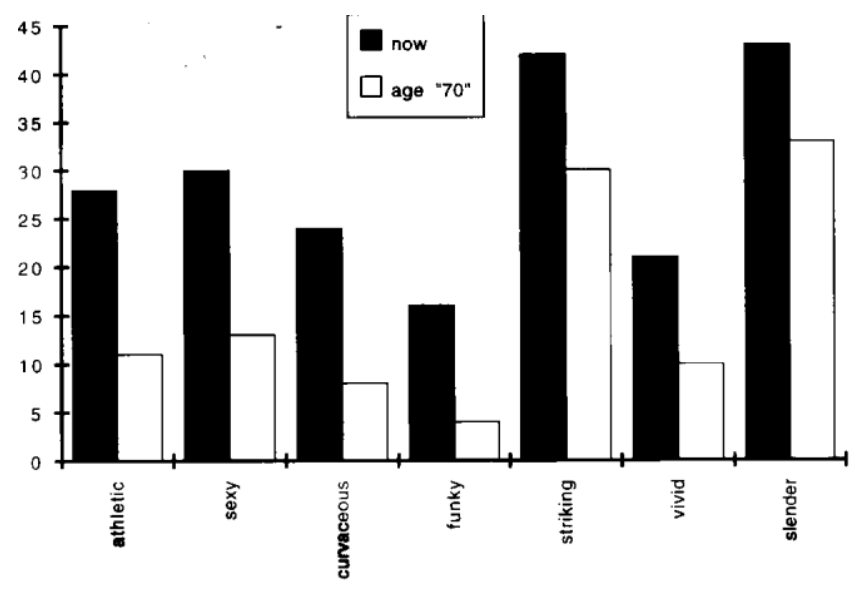

Figure 4. Comparison of responses to selected physical impressions: Summary of greatest decreases from now to age 70 .

As part of the questionnaire, students were given lists of adjectives-60 personality characteristics and 51 physical impressions-from which they could select as many as they thought were appropriate. Responses regarding adjective selection of personality characteristics and physical impressions were analyzed for differences and similarities

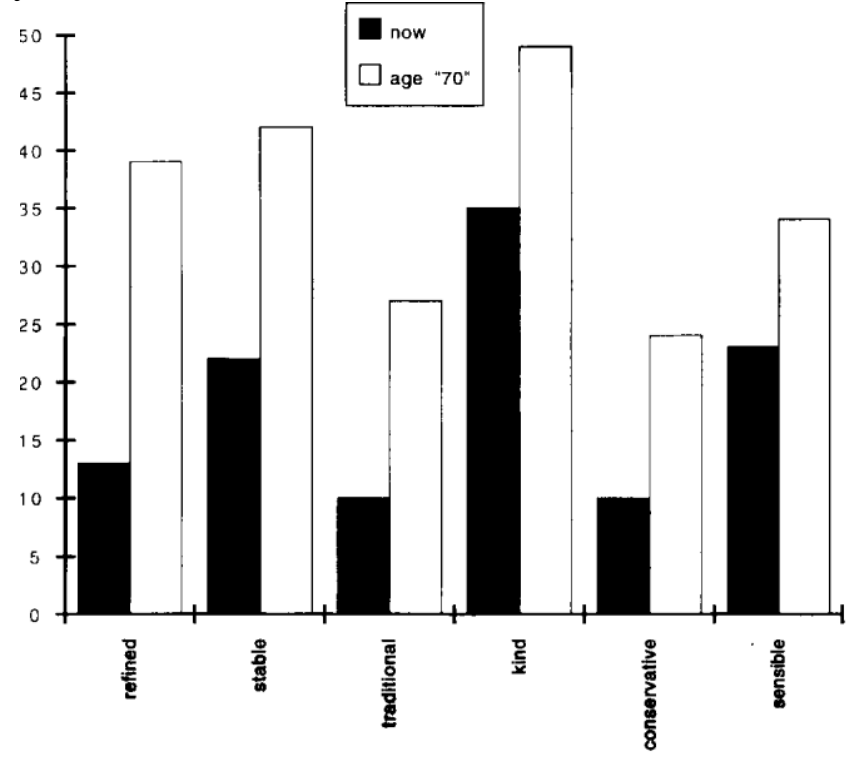

Figure 1. Comparison of responses to selected personality characteristics: Summary of greatest increases from now to age 70. 


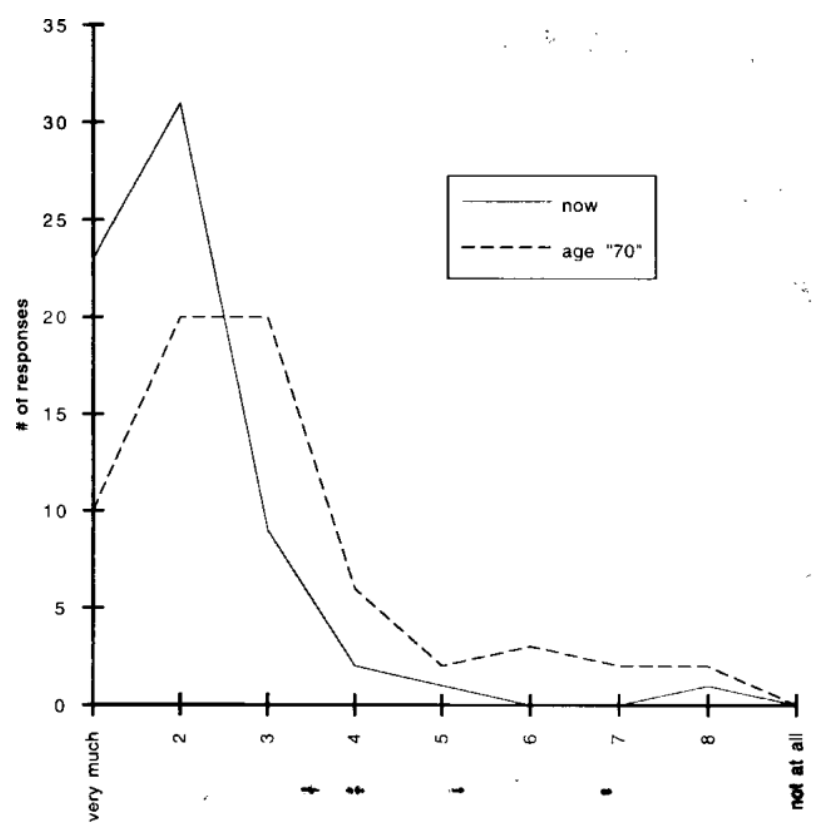

Figure 6. Summary of responses to the question: "How much does the clothing you wear affect how you feel about yourself?"

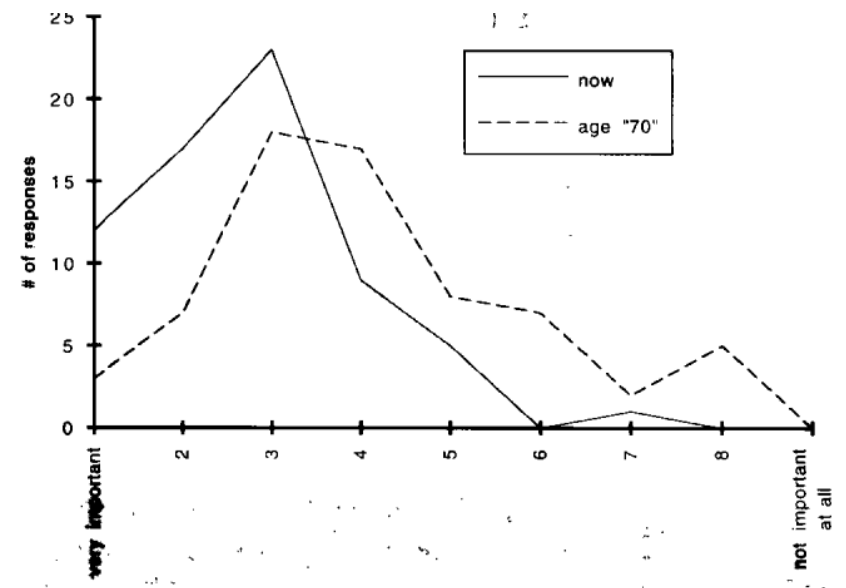

Figure 7. Summary of responses to the statement: "I think being in fashion is. .."

between students at their present age and at age 70. Figures 1, 2, 3, and 4 illustrate differences in a comparison of adjective responses between the present age and age 70 . The largest increases and decreases in responses to adjectives between present age and age 70 were measured in order to understand students' perception of change as a result of aging. Overall, in a comparison of responses, there is a general sense that students perceive the aging process will be a catalyst for development of differences in their personality characteristics and physical impressions. Comparison of responses to personality characteristics and to physical impressions suggest a move toward socially- and culturally-biased conceptions of an older population. The change in responses may reflect stereotypical images of older people presented by the media-such as more traditional, more conservative, more simple, and more classic- and the notion that one's image goals will be altered through the aging process. 
Figure 5 illustrates responses to the statement: "Describe the physical attributes that you feel are a strong point that you would like to emphasize with clothing." Descriptors used in the responses were organized, grouped, and analyzed to rank similarities and differences. According to the results, at the students' present age, the waist is the area of the body most emphasized; but at age 70 , the face becomes the most emphasized area. The focus on the face could simply mean that students perceive less need to focus on the body. Emphasis on the face could also correspond to a perceived difficulty in either finding clothes to fit the body satisfactorily, or an overall dissatisfaction with the body due to the aging process.

Figure 6 represents responses to the question: "How much does the clothing you wear affect how you feel about yourself?" Responses to this question were marked on a nine-point scale: for now they were higher on the scale than for age 70 . Yet, the highest response at age 70 falls in the plateau at the upper end of the scale and very near to the highest responses for now. This indicates a collective perception that clothing will still play an important role for these individuals at age 70 .

Figure 7 illustrates a collective response to the statement : "I think being in fashion is...". The responses at now and age 70 are very similar in graph form to Figure 6. Being in fashion seems to be relatively important at both ages; but again, at age 70 there is a slight plateau at the upper end of the scale. This could indicate that students perceive the motivation to "be in fashion" will decrease with age. It is also possible that the responses are connected to the lack of older models used to illustrate contemporary fashions in the media, and the perception that achieving a desirable level of fashionability may be more difficult at age 70. Another possibility for interpreting the outcomes

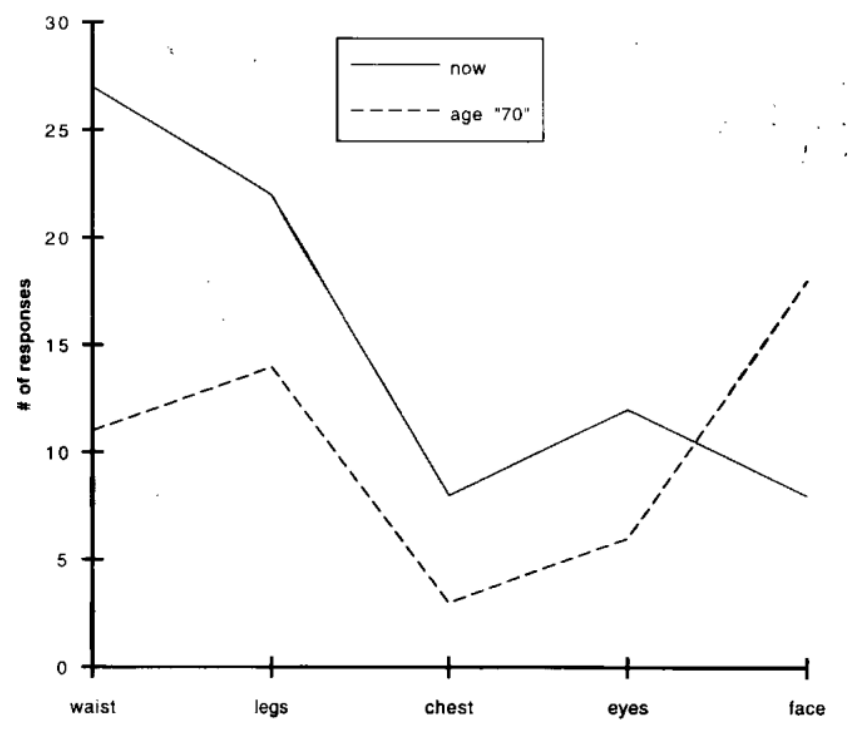

Figure 5. Summary of responses to the question: "What physical attributes do you like to emphasize with clothing?"

in Figures 6 and 7 is that students perceive themselves as having developed their own style by the age of 70 and may feel that clothing and being in fashion will still be important, but will not be as much of a focal point in their lives as it is currently. 


\section{Individual Responses which Represent the Range of Collective Responses to the Selection of Visual Images and Justifications}

The second part of the data focused on each student's ensemble for now and for age 70. Selfgenerated illustrations, photographs, total images cut from fashion catalogs or popular magazines, or a collage of images cut from magazines and catalogs were used by students to represent the ensemble chosen for designated events. Although many students created their own collage out of pictures and illustrations, only a few used an older model to illustrate their selection. Those students who created their own images tended to depict themselves as older, simply by drawing gray hair in place of their present hair color. The current lack of older models in the media may have pushed students to disregard the model altogether and only consider the clothing.

To provide instructors and students with a more complete description and justification of the image(s) selected, students were asked to respond to specific open-ended questions. In the analysis of student responses, the two ensembles selected for the designated event for now and age 70 were compared for similarities and differences. Some students chose ensembles that indicated little difference between appropriate clothing for their current age, and for their projection of themselves at age 70. Other students selected ensembles that illustrated a contrast between what they would wear at their present age and what they anticipated they would wear at age 70 . Further, images chosen and justifications for their selections often differed.

We analyzed students' ensembles by considering visual aspects of the entire ensemble as well as their justification for what was selected. Critical to this exercise was the amount of change between the ensemble for the student'ss present age and for age 70, and their justification for that change. Visual aspects that changed were: colors selected, amount of body exposed and definition of the clothing itself, as well as changes in physical coloring and bodily characteristics of the model.

Using data obtained from the visual images, a continuum was developed which allowed us to consider the amount of change between now and age 70; and thereby, to use it to evaluate students' acknowledgments of how they perceived the aging process would occur. In addition, it was a way for students to visually realize how their responses related to others in the class. Discussion of the exercise was then focused on such specific aspects as features of a shoe and how selections of heel height or cut of shoe could be an indicator of their perceptions of being "old," or whether and why they thought it would be necessary to change their preferred color scheme due to the aging process.

The left end of the continuum represents the least amount of alteration in ensemble and justification, indicating that those students perceived very little, if any, change in their appearance and manner of dress between their present age and age 70. Twelve out of 67 examples were placed closest to this end of the continuum. An example from this end of the continuum was a female student who chose a cotton sweat suit in navy blue at her present age to wear to a football game and a similar sweat suit in royal blue to wear to a football game at age 70. In her justification, she expressed a concern for comfort in her clothing at both ages. Both ensembles were featured on youthful models; yet the student justified her selection of the royal 
blue ensemble because of her gray hair at age 70 . Besides color, there were other subtle differences in the two ensembles. For example, both covered the same parts of the body, but the sweat suit for now contrasted an over-sized sweater with closely fitting slacks. The age 70 ensemble was more structured, with a button front opening on the top piece, which made it appear as a jacket worn over looser fitting slacks.

The largest portion of responses (44 of 67) were placed in the central area of the continuum. Responses located in the area to the left of center on the continuum reflected a realization of some of the effects of the aging process. Bodily changes due to aging were acknowledged and accommodated for by the students through clothing selection. For example, one female student chose a short, form-fitting, spaghetti strap slip dress with a surface covered with gold sequins to wear to a teen beauty pageant at her present age. She selected a somewhat looser and slightly longer tank dress in silver sequins, which was sleeveless, but less revealing of body curvatures, to attend the pageant at age 70 . The student felt that the dress would be more appropriate for age 70 due to the looser waist and bustline, while the longer hem would still be short enough to "show off her legs. While the form changed slightly, the student did acknowledge some anticipated changes in her body that would affect her image goals at age 70 .

Students' perceptions placed to the right of center on the continuum involved a greater change in their justifications of the selected ensembles through the manipulation of the ensemble as a result of the aging process. For example, a male student's response included an example of a suit for both ages to be worn to a funeral of a loved one. Both ensembles consisted of three pieces in a dark fabric: a jacket, shirt, and trousers. The ensemble for his present age was more informal, both visually and according to the student's justification. Through addition of a tie, a white dress shirt, and a more tailored jacket, the student indicated that this formal appearance would be more appropriate for him at age 70. In his justification, at age 70, his anticipated increase in economic status would create different image goals that would make the tailored suit more appropriate.

The far right end of the continuum represents an extreme change in ensembles selected and justifications, indicating that students perceive an absolute change in their appearance and manner of dress between their present age and age 70. Eleven out of the 67 responses comparing present age and age 70 fell onto this end of the continuum. Using visual examples and descriptions which could be considered stereotypical in both ensemble and justification, student responses at this end of the continuum seem to reflect generalized attitudes toward the aging process that are similar to those presented in the media. Toward this end of the continuum, evaluative words such as "conservative" and "moral" were used repeatedly by students to justify their ensemble at age 70 .

An illustrative example of the right end of the continuum involves a female student who was planning to attend the wedding of a friend. At her present age, the student selected an above-theknee, form-fitting, natural linen tank dress with a low and wide scooped neckline worn with a large brimmed straw hat. By contrast, for age 70 she selected a calf-length and loose pastel floral dress of indeterminate pattern worn by an elderly woman drinking a glass of orange juice. The student went beyond a simple acknowledgment of the realities of the aging process. Instead, she perceived it as causing radical changes in her clothing because of an anticipated change in body size and shape which needed to be concealed by dress. Her justification for the two selections 
corresponded with the visual images. She wrote that her image goals at age 70 were "more appropriate" for a person of that age, even though they were markedly different from those she discussed in her response for her selection at her current age. She admitted that these differences could be an embodiment of stereotypical images of how younger and older people should look in the U.S.

Students' responses to the questions in the first section tended to correspond with their visual examples. For example, a comparison was made of each student's responses to the questions "How much does the clothing you wear affect how you feel about yourself?" and "I think being in fashion is... " and their image selection and justifications. Each of the four students selected for discussion above responded to the nine-point scales in accordance with the degree of change in their ensembles and justifications. For example, the student who demonstrated little change in selected ensembles for both ages gave the same response to the question of the importance of fashion at her present age and at age 70. The student with a high level of change in her selected ensembles responded two spaces closer to "not very much" and "not important at all" on the nine-point scales at age 70 than at her present age.

Although this type of correspondence between an individual response to specific questions and placement on the continuum occurs with these two examples, it does not necessarily happen with all examples. Many students experienced some degree of difficulty in projecting themselves to age 70. Considering that stereotypes tend to be connected with entire groups of people rather than with individuals, students' initial responses may reflect more of a tendency to exhibit stereotypical group ideas when answering generalized questions. Planning a specific ensemble allowed for more involvement and the possibility for students to explore the older individual she or he might become.

\section{Implications for the Pedagogical Process}

This exercise provided a means to explore young adults' perceptions of the aging process and the relationship of older adults to the clothing market. When students were faced with the task of putting themselves into the body of a 70 year old, their own aesthetic response to this age group came into question at a very personal level. Statements made by students following completion of this project led to the realization that the process was effective in helping them move beyond personal perceptions, needs, and tastes. Although many of them resisted the idea of imaging themselves at the other end of the life span, their observations reflect an understanding of the importance of being open to needs of others. During class discussion at the completion of the project one student was reinforced by her classmates after voicing her opinion as follows: "I didn't really like the process of having to think of myself as an old woman. But I have to admit that this project made me start to look at the buying habits of others in a totally new light."

The experience of the project gave students an opportunity to evaluate their existing perceptions of the aging process. Following Brookfield's (1987) criteria for critical thinking, students were encouraged to challenge existing paradigms. Through the process of projection and imagination, students ultimately were able to explore their underlying biases and perceptions of others different from themselves. 
This exercise was developed to help guide students' thinking from the familiar to the unfamiliar, and to consider the importance of context in the application of the components of critical thinking. Three contexts were developed and specified: specific ages-now-ages-now and age 70 , designation of a specific event, and selection of ensembles for the chosen event for each age category. Within these contexts, assumptions and biases regarding the aging process were explored.

Though it was difficult for many students to find positive and fashionable role models in the media, much of the data from this project points to a general importance they place on looking good at both ages. The use of personal examples of older people, such as a grandparent, may have had implications for resulting perceptions of the aging process on the part of students. Except for extreme stereotypical responses on the far right of the continuum, students seemed to have more positive than negative perceptions of the aging process, and were particularly concerned with staying active as older individuals.

In analysis of descriptive and closed-ended responses from the first section of the questionnaire, some changes were indicated regarding the relationship of clothing and the body at the present age and at age 70. Comparison of each ensemble with students' justifications illustrated some correspondence of their individual responses throughout the several phases of the exercise. Overall, participants did have a general perception of limited clothing options for older people, however, while some students perceived they would be forced to wear clothing they considered stereotypical of an older age group, many others deviated little from their current style of dress when selecting clothing for age 70 .

This project was developed as a means of encouraging students to address needs and desires of older consumers ; a situation which might involve personal biases and professional challenges. As the literature on aging and stereotypes indicates, when a person looks at a group and group behavior, he or she might be inclined to hold and perpetuate stereotypes, however, if a person looks at a specific individual within the group, stereotypes will be less likely to form.

Students who participated in this in-class exercise consisted mainly of Caucasian females. The gender ratio reflects the overall proportion of females to males choosing to enroll in an aesthetics course. The proportion of Caucasians to other racial and ethnic groups reflects the overall demography of student population at this university as well as the area in the U.S. where the university is located, however, further use of this type of exercise within classrooms throughout the country could lead to a better understanding of perceptions of the aging process as they function within many diverse racial and ethnic groups and could, in turn, lead to the development of skills needed to overcome some challenges faced by minority groups throughout the aging process.

The students were not asked to predict what clothing would be like when they reached 70 years of age, around the year 2040. Instead, they were told to imagine themselves as age 70 at the present time. This eliminated the need to think on such questions as: "What will fashion be like in the year 2040? What changes will society have made in the next 50 years?". However, if we had asked students such questions, how would their responses have differed? Those kinds of questions require a more focused ability to project and imagine oneself in the future, taking many 
additional variables into consideration. Would retirement and travel rank as high if the students were told to project to the year 2040? The imagination could introduce variables that relate to such things as technological advancements. What if, in the year 2040, we will not travel per se, but rather use holographic imagery created in our homes to view any area of the world, at any given time? How would these changes affect our clothing selections and image goals?

This exercise in critical thinking required students to confront and explore their assumptions and biases related to older people and the aging process. Such a trigger exercise, according to Brookfield (1987), represents the first phase in thinking critically. It is also an appropriate exercise in an aesthetics class, because understanding responses, needs, and expectations of those we serve is a primary goal of aesthetics. Through personal projection and follow-up discussion of perceived and real clothing needs of individuals in later stages of the life cycle, we encouraged students to reach outside of their own skin.

In subsequent discussions, students said they enjoyed the exercise as an insightful means through which to project themselves in a different generation, however a few students expressed some difficulty perceiving themselves at age 70 . There were difficulties involved in challenging previously held biases about older people. To make the contextual leap of age, some students indicated a need to think of a grandparent or another familiar individual. Others explained, and even complained, that they found the exercise to be 'disconcerting', and one commented that it was even somewhat 'morbid.'

Helping students reflect on the process of projecting themselves into another generation is one way to encourage students to think critically. Reflective types of discussion questions might include: What are some things you've learned about yourself through this project? What are possible myths regarding the aging process that permeate the media and the clothing industry? As a professional in the clothing industry, how could you dispel such myths? How would you deal with cultural biases and stereotypes connected with consumers whom you will serve? What are some real changes that should be anticipated? How could clothing be designed and merchandised to recognize-but not magnify-the aging process? Applying the Tofflers' "Third Wave" concept, what changes would occur in the apparel industry within a de-massified society?

Research on old age and the aging process indicates that, not only have attitudes of older people changed over the course of several decades, but their behavior has changed as well (Belsky, 1988; Friedan, 1993; Laslett, 1989; London, 1990). Travel and education are often combined to create opportunities for older people to continue to be active. Exercise, diets, and improvements in the field of medicine have increased life expectancy, activity and health among older individuals. These actions of older consumers defy stereotypical images that form when groups become categorized. Yet, are they enough to influence our understanding of realities and myths of the aging process and our ability to work with older consumers?

To explore and examine students' reactions to an actual older consumer, we developed a subsequent exercise. Students were asked to complete the exercise, only this time they "interviewed" the same 75 year-old client. For this exercise, we selected a robust female who visited our class two weeks in succession. She chose two events- cross-country skiing and traveling to Holland during the tulip season-and students were to plan appropriate ensembles 
based on what they learned while interviewing her. The woman answered students' questions regarding her preferences and lifestyle. She responded to slides of clothing that were purposely selected for their range: some examples were conservative or traditional images that students might associate with the elderly, while others contrasted in color, textures, shapes and lines. She also was shown examples from the students' previous exercises, where they dressed themselves for now and for age 70. By providing students access to a particular individual who did not fit into stereotypical images of 'old age,' they were able to further consider their existing ideas of older consumers.

Teaching students to think critically can be difficult, yet it is rewarding for both instructors and students. The process is demanding from both perspectives, but we believe the benefits are worth the challenge. If exercises in critical thinking were developed in other areas of textiles and clothing and used more often in classrooms, students would become familiar and comfortable with the process. Other groups that have marketing implications could be explored in this same manner. Though critical thinking and aesthetics proved compatible in terms of objectives, other areas of our field need to be explored. Such multiple experiences could have impact on students in their intellectual development, and would be an area for further application in the classroom.

\section{References}

Arnheim, R) (1974)) Art and visual perception) Berkeley: University of California Press) Atkins, T) V), Jenkins, M) C), \& Perkins, M) H) (1990)) Portrayal of persons in television commercials age 50 and older) Psychology, A Journal of Human Behavior, 27(4), 30-37) Bass, S) A), Kutza, E) A), Torres-Gil, F) M) (1990)) Diversity in Aging) Illinois: Scott Foresman)

Bassili, J) N), \& Reil, J) E) (1981)) On the dominance of the old age stereotype) Journal of Gerontology, 36(6), 682-688)

Belsky, J)J. K) (1988)) Here tomorrow: Making the most of life after fifty) Baltimore: The Johns Hopkins University Press)

Bos, E), Vu, M) T), Massiah, E), \& Bulatao, R) A) (1994)) World population projections 19941995: Estimates and projections with related demographic statistics) Baltimore: The Johns Hopkins University Press)

Brookfield, S) D) (1987)) Developing critical thinkers: Challenging adults to explore alternative ways of thinking and acting) San Francisco: Jossey- Bass)

Brookfield, S) D) (1990)) The skillful teacher: On technique, trust and responsiveness in the classroom) Oxford : Jossey-Bass)

Chaffee, J) (1992, Spring)) Teaching critical thinking across the curriculum) New Directions for Community Colleges, 25-35)

Clayton, R), Lennon, S), \& Larkin, J) (1987)) Perceived fashionability of a garment as inferred from the age and body type of the wearer) Home Economics Research Journal, 15(4), 237-246) DeLong, M) R) (1987)) The way we look: A framework for visual analysis of dress) Ames, IA: Iowa State University Press)

Eaton, M) M) (1988)) Basic issues in aesthetics) California : Wadsworth)

Ennis, R) H) (1993)) Critical thinking assessment) Theory Into Practice, 32(3), 179-186)

Fennell, V) (1994)) Meanings of aging in a southern town) In N) Sault (Ed)), Many mirrors: Body image and social relations (pp) 155-174)) New Brunswick, NJ: Rutgers University Press) 
Fiore, A) M), Moreno, J) M), \& Kimle, P) A) (in press)) Aesthetics: A comparison of the state of the art outside and inside the field of textiles and clothing) Part two: Object) Clothing and Textiles Research Journal)

Friedan, B) (1993)) The fountain of age) NY: Simon \& Schuster)

Gallo, D) (1989)) Educating for empathy, reason and imagination) The Journal of Creative

Behavior, 23(2), 98-115)

Halpern, D) (1993)) Assessing the effectiveness of critical thinking instruction) The Journal of General Education, 42(4), 238-254)

Jackson, H) O), \& O’Neal, G) S) (1994, Summer)) Dress and appearance responses to

perceptions of aging) Clothing and Textiles Research Journal, 12, 8-15)

Knight, C) L) H) (1992, Spring)) Teaching critical thinking in the social sciences) New

Directions for Community Colleges, 63-73)

Laslett, Peter) (1989)) Afresh map of life: The emergence of the third age) London: Weidenfeld

\& Nicolson)

Laughlin, J) S) (1992, Spring)) When students confront the experts: Toward critical thinking)

English Journal, 72-75)

Levin, W) C) (1988)) Age stereotyping: College student evaluations) Research on Aging, 10(1), 134-148) London, M) (1990)) The second spring of your life: How

you can make your middle years joyous and productive) NY: Continuum)

McPeck, J) E) (1990)) Teaching critical thinking: Dialogue and dialectic) London: Routledge)

Menefee, E) (1987, Winter)) Becoming optimally human: An approach toward critical thinking)

Et Cetera, 335-338)

Munro, T) (1956)) Toward science in aesthetics) NY: The Liberal Arts Press)

Paul, R) (1992, Spring)) Critical thinking: What, why and how) New Directions for Community Colleges, 3-23)

Powell, L) A), \& Williamson, J) B) (1985, Summer)) The mass media and the aged) Social Policy, 38-49)

Ruggiero, V) R) (1988)) Teaching thinking across the curriculum) NY: Harper \& Row)

Shim, S), \& Bickle, M) C) (1993)) Women 55 years and older as Catalog shoppers: Satisfaction with apparel fit and catalog attributes) Clothing and Textiles Research Journal, 11(4), 53-64)

Tibbitts, C) (1979)) Can we invalidate negative stereotypes of aging? The Gerentologist, 19(1), 10-20)

Toffler, A), \& Toffler, H) (1995)) Creating a new civilization : The politics of the third wave)

Atlanta: Turner Publishing) U)S) Bureau of the Census) (1992, November)) 1990

Census of population: General population characteristics of United States) U)S) Department of

Commerce) Walters, K) S) (1990)) Critical thinking and the Spock fallacy) Innovative Higher

Education, 15(1), 17-28)

Workman, J) E), \& Johnson, K) K) P) (1989, Fall)) The role of clothing in perpetuating ageism) Journal of Home Economics, 11-15) 